\title{
Dichrooscytus fervens sp. n., a new species of Miridae (Hemiptera, Heteroptera) from Finland
}

\author{
Arto Muinonen, Veikko Rinne \& Eero Vesterinen
}

Muinonen, A., Rinne, V. \& Vesterinen, E. 2019: Dichrooscytus fervens sp. n., a new species of Miridae (Hemiptera, Heteroptera) from Finland. - Entomol. Fennica 30: 159-167. https://doi.org/10.33338/ef.87171

Dichrooscytus fervens Muinonen \& Rinne sp. n. (Hemiptera: Heteroptera: Miridae) is described based on material collected in Finland between 2011 and 2018. A morphological description is provided along with DNA barcodes (COI gene) and a phylogeny of all the Dichrooscytus species for which a DNA barcode is available. The new species lives on Picea spp. and is still known only from Finland. A map of all the records is given, as well as an identification key of the Dichrooscytus species occurring in northern Europe.

A. Muinonen, Everlahdentie 58 E 14, 57710 Savonlinna, Finland; E-mail: artomuinonen@gmail.com

V. Rinne, Zoological Museum, 20014 University of Turku, Finland; E-mail: veikko.rinne@utu.fi

E. Vesterinen, Biodiversity Unit, 20014 University of Turku, Finland; E-mail: ejvest@utu.fi

Received 14 December 2018, accepted 14 January 2019

\section{Introduction}

The suborder Heteroptera (Insecta: Hemiptera) is a large group of insects with over 45,000 described species worldwide (Henry 2017). The genus Dichrooscytus Fieber, 1858 belongs to Miridae, the largest heteropteran family with over 1,500 genera and over 11,100 species (Schuh 2002-2013, Henry 2017). The species in the genus Dichrooscytus are mostly 4-6 mm long and green with more or less red and brown colouration in hemelytra.

There are both Palaearctic and Nearctic species in the genus. The Palaearctic Dichrooscytus species have a diagnostic aedeagus compared to the Nearctic ones (Josifov 1974). There are two sclerotized appendages in the aedeagus of the Palaearctic species, but not in that of the Nearctic species. One appendage is a long spicule and the other one is apically heavily denticulate. The latter is called a denticulate appendage in this paper.

According to Kerzhner and Josifov (1999), there are 25 Palaearctic species in Dichrooscytus. Josifov (1974) gave detailed information about all the Palaearctic species known at that time and provided a key to identify them. He also described six new species and a new subspecies, $D$. algiricus bureschi, which was later upgraded to the species $D$. bureschi Josifov, 1974 by Günther (1990). Four Palaearctic Dichrooscytus species have been described after Josifov (1974): D. gustavi Josifov, 1981, D. impros Heiss, 1988, D. helanensis Qi \& Nonnaizab, 1996 and D. josifovi Kerzhner, 1997. All the Palaearctic species live on coniferous trees, many of them on Juniperus spp. (Josifov 1974).

Three Dichrooscytus species have previously been found in northern Europe and occur in Fin- 
land: D. rufipennis (Fallén, 1807), D. intermedius Reuter, 1885 and D. gustavi. Dichrooscytus rufipennis is a common species in Finland living on Pinus sylvestris, D. intermedius lives mainly on Picea abies and D. gustavi on Juniperus communis and Thuja spp. The latter two have become more common in southern Finland in the last ten years (Rintala \& Rinne 2011, Hemiptera Expert Group 2018).

In this paper, we describe a new species Dichrooscytus fervens Muinonen \& Rinne sp. n., found for the first time in 2011 in Finland.

\section{Materials and methods}

\subsection{Field work and morphological analysis}

Adults were collected by using sweep nets mainly by the first author. Specimens used in morphological studies were killed by freezing and stored in $70 \%$ ethanol for following examination. The specimens were photographed with a Canon EOS 7D camera attached to an Olympus SZX16 stereomicroscope at the Zoological Museum, University of Turku, Finland. The camera was driven by a QuickPHOTO MICRO 3.1 software. Measurements were taken from six males and three females with the same software. Images were stacked using Zerene Stacker and CombineZP software.

The aedeagus of 11 males were examined. The tip of the spicule was broken in two of the examined aedeagi, pointing out of the importance of studying multiple specimens. Genitalia were photographed after being cleared in $\mathrm{KOH}$ solution.

\subsection{Laboratory work}

To allow easier DNA-based identification and comparison to other Dichrooscytus species, we amplified and sequenced the so called DNA barcode region (the first half of mitochondrial cytochrome oxidase subunit I gene, COI) for our type specimens as follows. DNA was extracted from two fresh samples (BIFFI022-12 and BIFFI023-12, male holotype and female paratype; Table 1) using a modified salt-extraction pro- tocol following Pilipenko et al. (2012) and Aljanabi and Martinez (1997). The lab and the equipment were sterilized before each extraction batch. For each extract, we amplified the DNA barcode region using LCO1490/HCO2198 (Folmer et al. 1994). The following PCR setup was used for all samples: $2 \mu 1$ of the template DNA was mixed with $420 \mathrm{nM}$ of each primer, $5 \mu \mathrm{l}$ of 2x KAPA2G HS Ready Mix (KAPA Biosystems Inc., Wilmington, Massachusetts, USA) and the reaction was filled up to $12 \mu 1$ with sterile water. The PCR cycling conditions were as follows: initial denaturation for $5 \mathrm{~min}$ in $95^{\circ} \mathrm{C}$, then 40 cycles of denaturation for $30 \mathrm{~s}$ in $95^{\circ} \mathrm{C}$, annealing for $30 \mathrm{~s}$ in $50{ }^{\circ} \mathrm{C}$, and elongation for $30 \mathrm{~s}$ in $72{ }^{\circ} \mathrm{C}$, ending with final elongation step for 10 min in $72{ }^{\circ} \mathrm{C}$. A blank control was included in each PCR batch. Successful PCR products were cleaned by adding $1 \mu 1$ of Exonuclease I and $1 \mu \mathrm{l}$ of FastAP (both included in the A'SAP clean kit; product nr 80350, ArcticZymes, Trømssa, Norway) to each product, and by heating the mix to $37^{\circ} \mathrm{C}$ for $10 \mathrm{~min}$ and $85^{\circ} \mathrm{C}$ for $5 \mathrm{~min}$. After that, sequences were shipped to Macrogen Europe (Macrogen, Seoul, Rep. of Korea) for sequencing.

For other samples (totalling 8 species and 40 specimens including 3 specimens of Dichrooscytus fervens sp. n. worked by the University of Oulu; Table 1) DNA barcodes were obtained at the Canadian Centre for DNA Barcoding. Legs or 2-3 abdominal segments of the specimens were placed in 96\% ethanol in a 96-well lysis microplate and dispatched to the Biodiversity Institute of Ontario where DNA was extracted and sequenced using standard protocols and primers (deWaard et al. 2008). All the sequences produced in this study are publicly available on BOLD (Ratnasingham \& Hebert 2007) under Barcode Index cluster BOLD:ACA9823 (DOI: dx.doi.org/10.5883/BOLD:ACA9823).

\subsection{Genetic analysis}

To construct the Dichrooscytus phylogeny, we downloaded all sequences from BOLD (Hebert 2003) databases and aligned them with our own sequences using MUSCLE plugin (Edgar 2004) in Geneious R11 (Kearse et al. 2012). We retained only unique and at least $500 \mathrm{bp}$ sequences 
Table 1. Dichrooscytus samples analysed in this study, with ProcessIDs of BOLD. Dichrooscytus rufipennis is a Palaearctic species, which has spread to North America (Josifov 1974).

\begin{tabular}{|c|c|}
\hline Origin/Species & ProcessIDs \\
\hline \multicolumn{2}{|l|}{$\begin{array}{l}\text { Palearctic species } \\
\text { Finland }\end{array}$} \\
\hline $\begin{array}{l}\text { D. fervens sp. } \mathbf{n} \text {. } \\
\text { Germany }\end{array}$ & BIFFI022-12, BIFFI023-12, LEFIJ3136-15, LEFIJ4340-16, LEFIJ4343-16 \\
\hline D. gustavi & FBHET196-11 \\
\hline D. intermedius & EUBUG1161-12, EUBUG1194-12 \\
\hline D. rufipennis & HCNC377-09, HCNC379-09, SMTPL3823-15 \\
\hline \multicolumn{2}{|l|}{$\begin{array}{l}\text { Nearctic species } \\
\text { Canada }\end{array}$} \\
\hline D. elegans & $\begin{array}{l}\text { BARSF399-16, BARSL013-16, CNBPK373-13, HCNC361-09, HCNC362-09, } \\
\text { HCNC364-09, HCNC367-09, HCNCS630-09, OPPOC967-17 }\end{array}$ \\
\hline D. latifrons & $\begin{array}{l}\text { CNKTA1114-14, CNLMD1790-14, CNPEC023-14, CNYOA170-15, } \\
\text { CNYOA173-15, CNYOB905-15, CNYOB913-15, CNYOI001-15, CNYOI010-15, } \\
\text { CNYOI012-15, HCNCR001-09, HCNCR002-09, HCNCR004-09 }\end{array}$ \\
\hline D. rainieri & $\begin{array}{l}\text { CNBFC048-15, CNBFD128-15, CNBFO815-15, CNYOJ1073-15, } \\
\text { HCNCS195-09, HCNCS196-09, HCNCS197-09, SSBAB1111-12 }\end{array}$ \\
\hline D. repletus & HCNCR015-09, OPPUG1308-17, SMTPI2477-14 \\
\hline $\begin{array}{l}\text { Outgroup species } \\
\text { Germany } \\
\text { Rhabdomiris striatellus }\end{array}$ & EUBUG793-11 \\
\hline
\end{tabular}

for each species. One sequence was removed from the analysis as an obviously wrong identification or mislabeling in the BOLD. Bayesian phylogenetic analyses were carried out using the MrBayes (Huelsenbeck \& Ronquist 2001) plugin in Geneious. The GTR+G (with four rate categories for Gamma) model of substitution was fitted and the data was subjected to two runs of one million generations each, with every $1,000^{\text {th }}$ generation sampled and the first 2,500 sampled generations discarded as burn-in. Similarly, we constructed a maximum-likelihood tree with 1,000 bootstrap replicates (other settings as default) using PhyML (Guindon \& Gascuel 2003) plugin using Geneious R11. The posterior probability tree from Bayesian analysis and consensus tree from ML were retrieved and used to draw the final tree. Moreover, the genetic distance based on COI sequences were calculated within all Dichrooscytus fervens sp. n. sequences and between $D$. fervens $\mathbf{s p .} \mathbf{n}$. and its closest relative in the tree. We also checked all our D. fervens sp. n. by comparing them to the GenBank nt database using online BLAST to find potential undescribed similar sequences (Altschul et al. 1990).

\section{Results}

\subsection{Description of Dichrooscytus fervens Muinonen \& Rinne sp. n.}

Type material. Holotype male: Finland, Mikkeli $\left(61^{\circ} 42^{\prime} \mathrm{N}, 27^{\circ} 23^{\prime}\right.$ E) 1.VII.2011, A. Muinonen leg. Paratypes, 12 males and 3 females: 2 males and 1 female, Finland, Mikkeli $\left(61^{\circ} 42^{\prime}\right.$ N, $27^{\circ} 23^{\prime}$ E) 1.VII.2011, A. Muinonen leg.; 6 males, Finland, Mikkeli $\left(61^{\circ} 42^{\prime}\right.$ N, $27^{\circ} 23^{\prime}$ E) 20.VI.2018, A. Muinonen leg.; 1 male, Finland, Savonlinna (615' N, 2848' E) 23.VI.2018, A. Muinonen leg.; 2 males, Finland, Siilinjärvi (630. $4^{\prime}$, $27^{\circ} 40^{\prime}$ E) 24.VI.2018, A. Muinonen leg.; 1 fe-

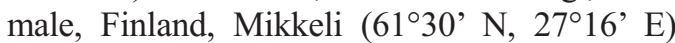
24.VI.2018, Petri Parkko leg.; 1 female and 1

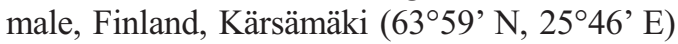
25.VI.2018, Petri Metsälä leg. All types in coll. of the Zoological Museum of the University of Turku (ZMUT).

Diagnostics. Dichrooscytus fervens sp. n. can easily be distinguished from the other species of the genus. The green scutellum, the largely red brown and often banded corium and the red patch 


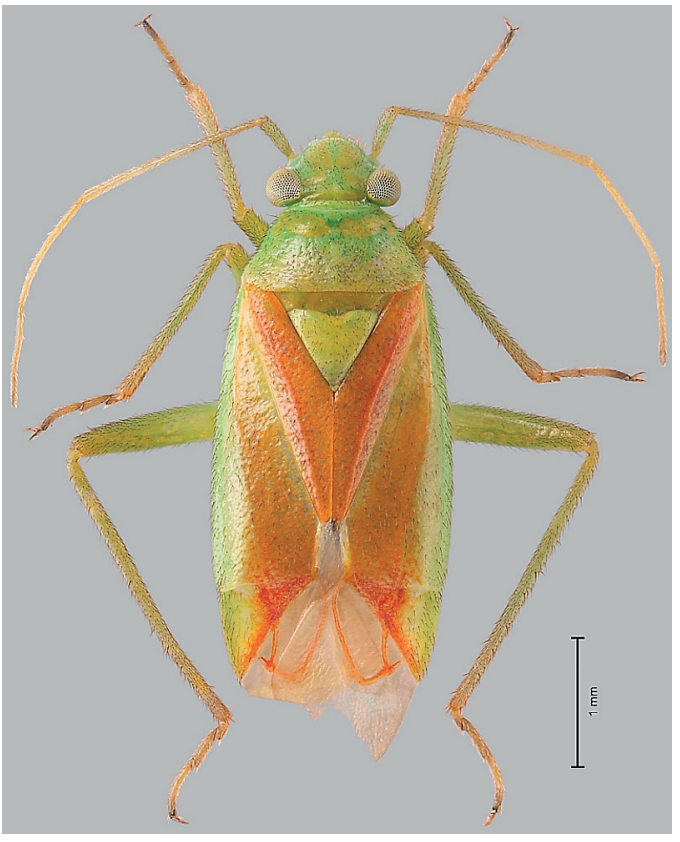

Fig. 1. Dichrooscytus fervens sp. n. male; paratype collected from Mikkeli on 1.VII.2011.

in the cuneus give the species a unique appearance. The combination of a slender, smooth and moderately curved spicule and an apically rounded denticulate appendage with a short spine distinguishes the aedeagus of $D$. fervens sp. $\mathbf{n}$. from all other described Dichrooscytus species (see Josifov 1974, Wagner 1974, Josifov 1981, Heiss 1988, Qi \& Nonnaizab 1996).

Description. Length 4.8-5.1 mm (6 males, holotype $5.1 \mathrm{~mm}$ ), 5.0-5.3 $\mathrm{mm}$ (3 females). Body oval (Figs. 1, 2).

Head green, covered with black hairs. Head width $1.0 \mathrm{~mm}$ ( 6 males including holotype), 1.1 $\mathrm{mm}$ (3 females). Vertex width $0.49-0.52 \mathrm{~mm}(6$ males, holotype $0.50 \mathrm{~mm}$ ), $0.53-0.57 \mathrm{~mm}$ (3 females). Antennae long, slender and green with light hairs. Length of the $2^{\text {nd }}$ antennal segment 1.6-1.8 $\mathrm{mm}$ (6 males, holotype $1.7 \mathrm{~mm}$ ), 1.7-1.8 $\mathrm{mm}$ (3 females). Proportions of antennal segments $21-25: 100: 53-61: 39-50$ (6 males, holotype $23: 100: 61: 46), 22-24: 100: 56-61: 45-$ 49 ( 3 females). Length of rostrum $2.3-2.4 \mathrm{~mm}(6$ males, holotype $2.4 \mathrm{~mm}$ ), 2.4-2.6 mm (3 females). Rostrum reaches beyond hind coxae. hairs.

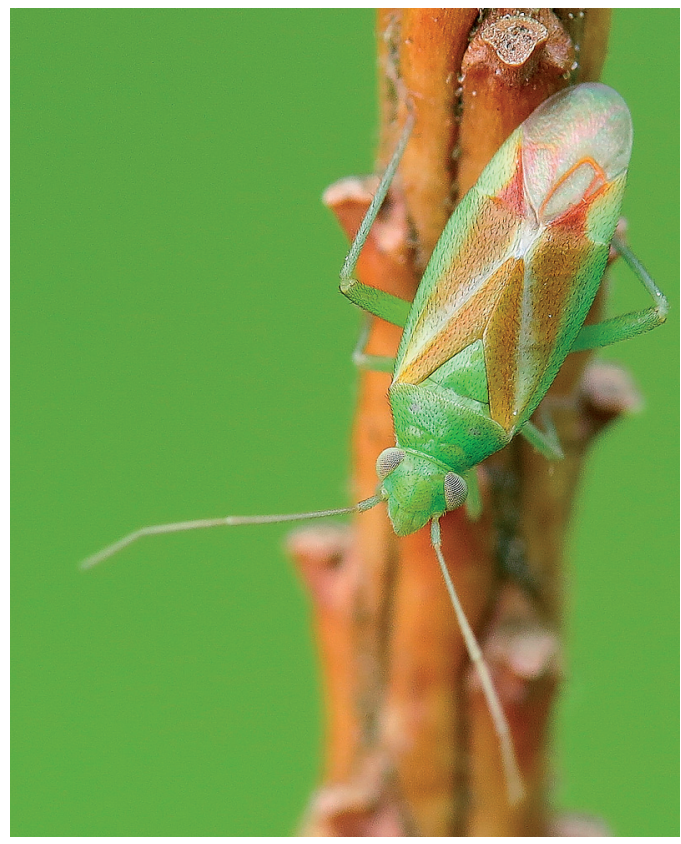

Fig. 2. A living specimen of Dichrooscytus fervens sp. $\mathbf{n}$. showing the diagnostic colour features: the green scutellum, the largely red brown and banded corium and the red patch in the cuneus. Photo: Petri Metsälä.

Hemelytra covered with black hairs. Clavus red brown. Corium largely red brown, costal margins green. Area near corio-claval suture often yellow green and then elongate patches in three different colours on corium making a banded appearance. Outer part of cuneus green, inner part with a triangular patch of red extending as a narrow line along at least $2 / 3$ of inner margin. Hemelytral membranes grey, veins of membranes orange red.

Legs green. Tarsi darker, greyish green. Shorter black hairs and some longer light hairs on femora. Tibiae densely covered with black hairs. Light brown spines on meso- and metatibiae. Third segment of tarsus as long as first and second segments together.

Dorsal side of abdomen mainly black, connexivum and last segment green. Ventral side of abdomen green. Pubescence of abdomen light.

Male genitalia (Fig. 3). Aedeagus with a spicule and a denticulate appendage. Long spicule is only moderately curved. No teeth or spines on spicule. Apical end of spicule sharp. Denticulate appendage of aedeagus apically rounded with a 


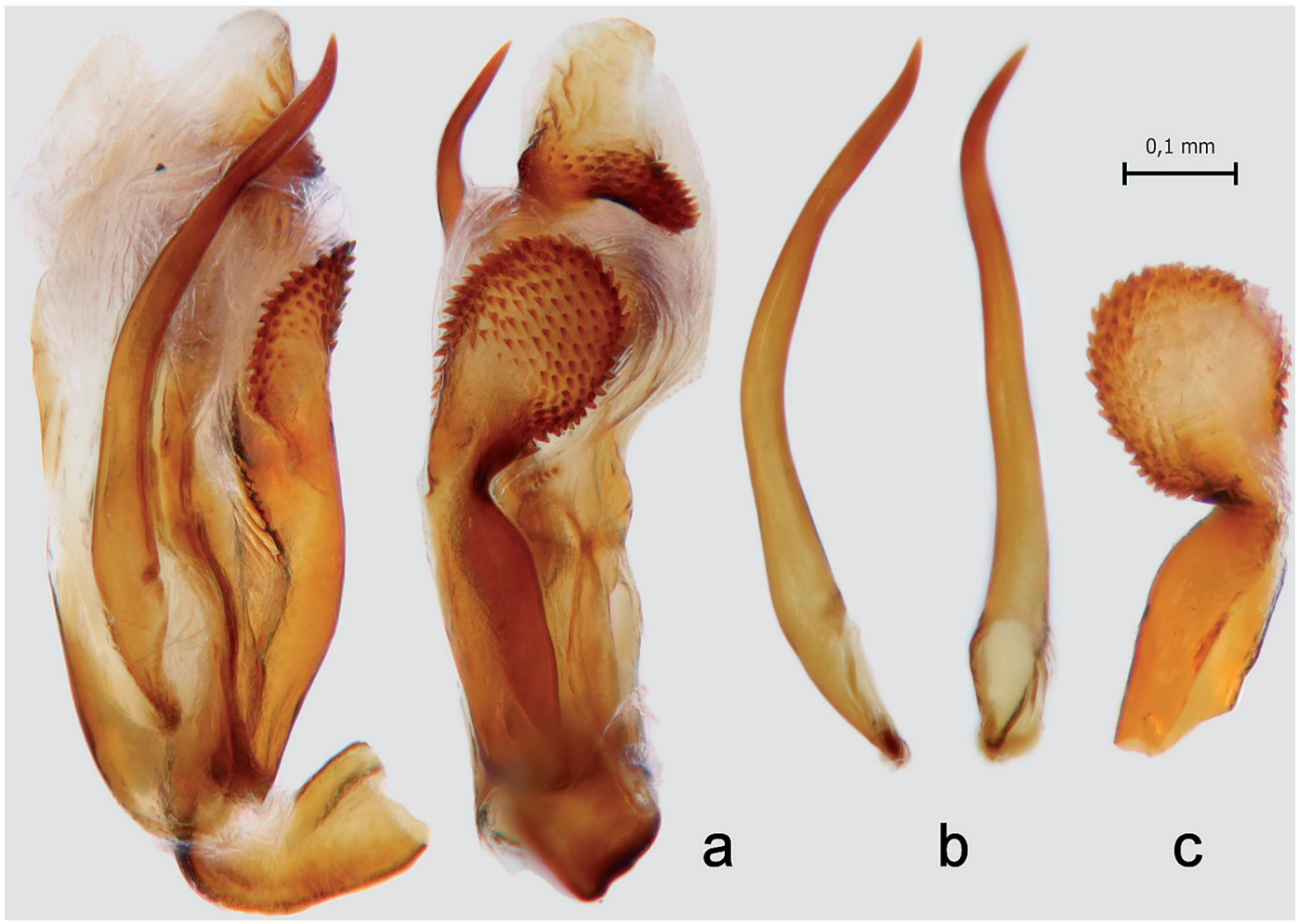

Fig. 3. Male genitalia of Dichrooscytus fervens sp. n. - a. Aedeagus from different angles. - b. Spicule from two different angles. $-c$. Underside of the dentaculate appendage. Paratypes: $a$ and b, collected from Mikkeli on 20.Vl.2018; c, same as in Fig. 1.

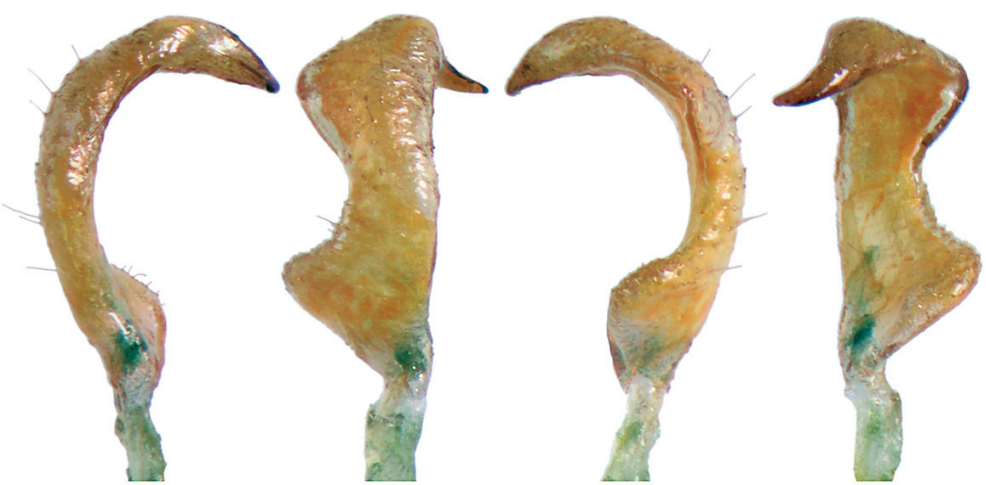

Fig. 4. Left (above) and right (below) parameres of Dichrooscytus fervens sp. $\mathbf{n}$. from different angles; same paratype as in Fig. 1.
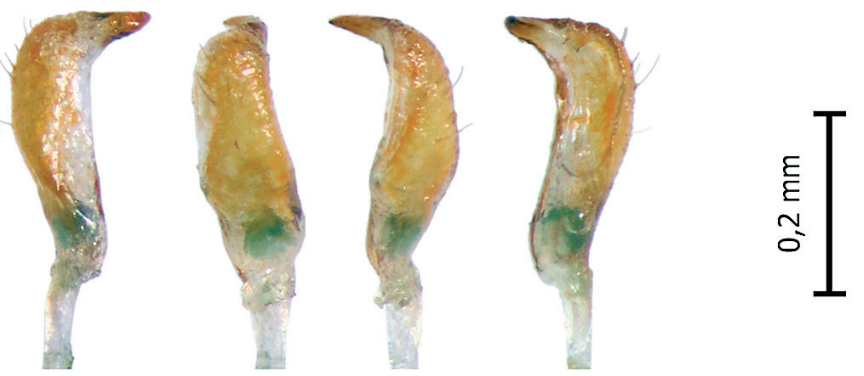


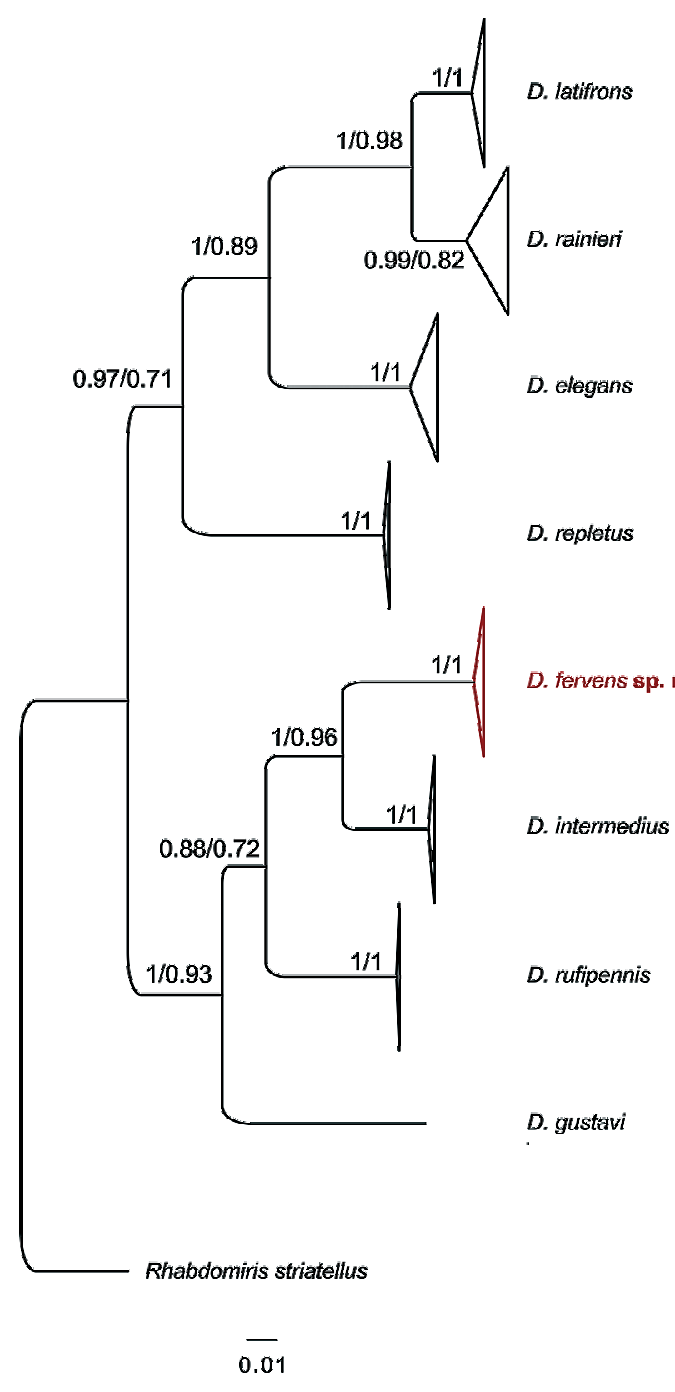

Fig. 5. A collapsed phylogeny of the genus Dichrooscytus using mitochondrial $\mathrm{COI}$ gene with support values for all the species based on both Bayesian posterior probability (left number) and maximum-likelihood analysis with 1,000 bootstrap replicates (right). Rhabdomiris striatellus (Fabricius) as an outgroup to root the tree. Our analysis supports the hypothesis of the new species, $D$. fervens. The scale refers to $1 \%$ genetic distance.

short spine on underside of rounded part. Parameres in Fig. 4.

Etymology. The red patch of the cuneus looks like a flame, so the new species has been given the name fervens, which means burning or glowing in Latin.

Ecology. The species lives on Picea abies in gardens and parks. It has especially been found in

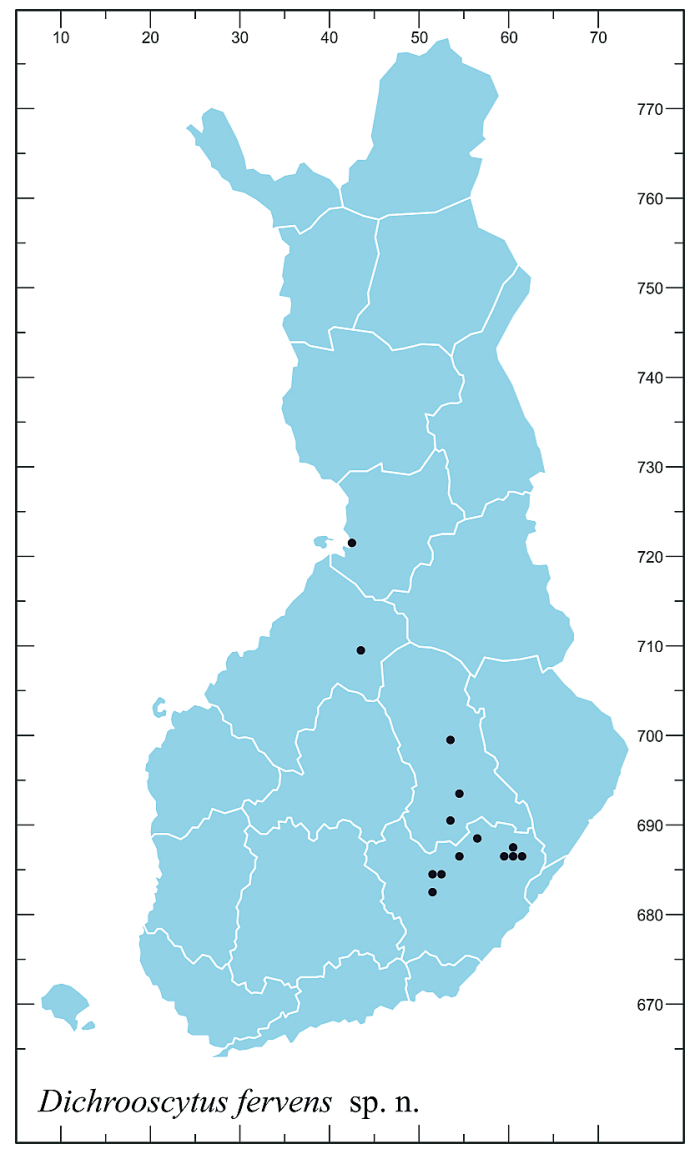

Fig. 6. Map of all the records of Dichrooscytus fervens sp. n., all in Finland. The dots represent $10 \times 10 \mathrm{~km}^{2}$ squares with observations of the species. Finland Uniform Coordinate System (YKJ), long tick marks with $100 \mathrm{~km}$ interval.

hedges in warm, sunny places. A few specimens have been found on Picea glauca in two places in Oulu, so the species presumably lives on different Picea species.

\subsection{Genetic analysis}

Phylogeny based on the DNA barcode region of the COI gene supports the novel species status of D. fervens sp. n. (Fig. 5). In the phylogenetic tree, $D$. intermedius clustered as the closest relative of $D$. fervens $\mathbf{s p .} \mathbf{n}$. The average genetic distance between all the $D$. fervens sp. n. samples in this study was $0.30 \%(S . D . \pm 0.13)$. On the other hand, distance to the samples of the closest relative (nearest neighbour) in the BOLD database, 

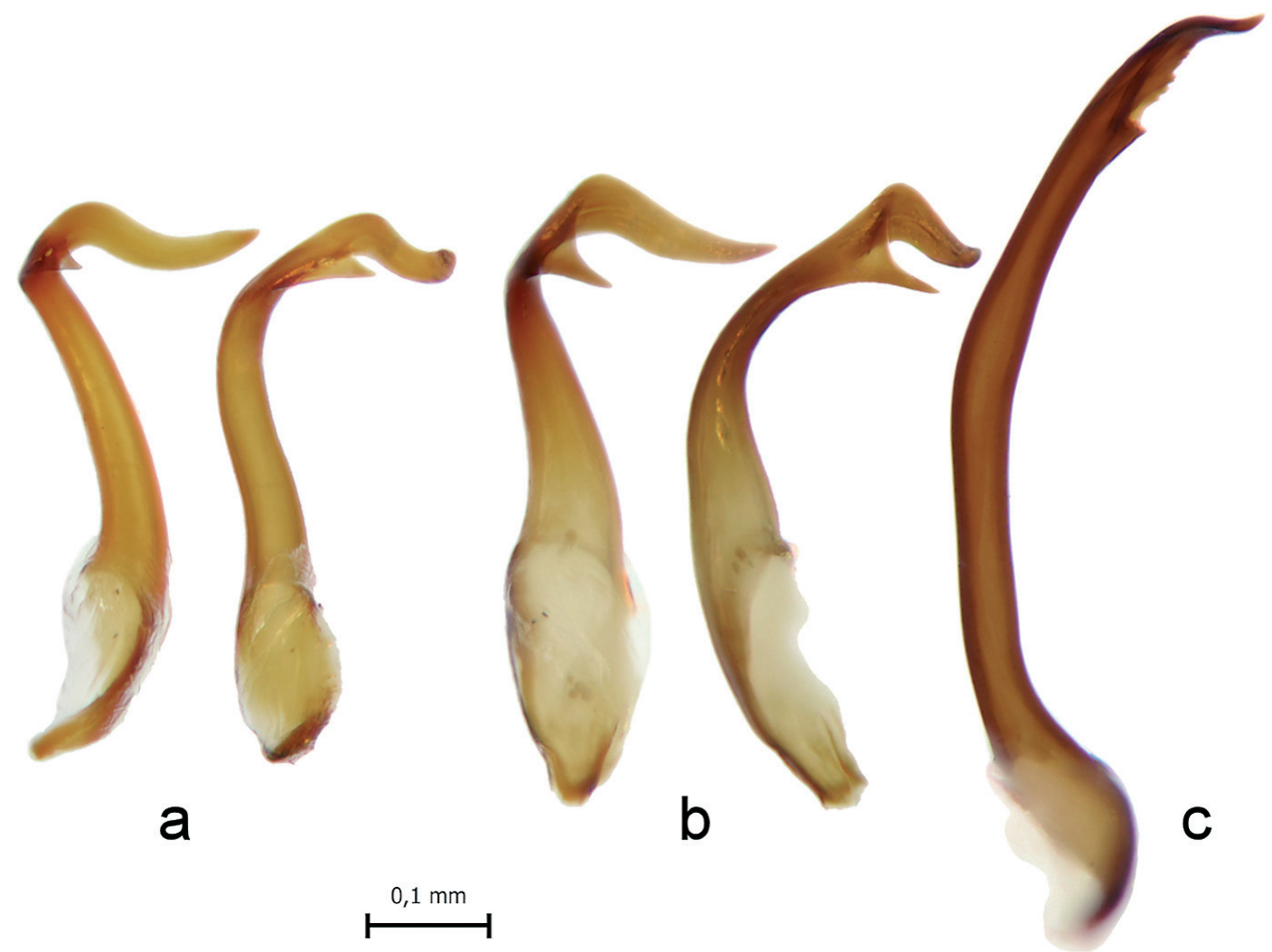

Fig. 7. Spicules of the aedeagus of three Dichrooscytus species. - a. D. gustavi (two different angles). - b. D. intermedius (two different angles). - c. D. rufipennis.

D. intermedius, was $7.56 \%$ (SD \pm 0.10$)$ indicating a clear barcode gap between these species. In the GenBank nt database, the nearest matches were for the $D$. intermedius records with approximately $93 \%$ similarity.

\subsection{Known observations Dichrooscytus fervens sp. n. from Finland}

No records from outside of Finland are known. The map of all the records is given in Fig. 6 .

The following abbreviations are used below for the collectors: $\mathrm{AM}=$ Arto Muinonen, $\mathrm{HN}=$ Harry Nyström, MM = Marko Mutanen, PM = Petri Metsälä, PP = Petri Parkko, PR = Pekka Raukko, $\mathrm{SH}=$ Sami Haapala, $\mathrm{TV}=$ Tuomo Vainio.

Mikkeli, Visulahti-Norola (61 $42^{\prime}$ N, $27^{\circ} 21-23^{\prime}$ E): 13 observations in two places between 2011 and 2018 (AM, TV, PM, PP, PR). The first record 17.VI.2011 3 exx. (AM). Most numerous 20.VI. 201880 exx. (AM).

Mikkeli, Ristiina $\left(61^{\circ} 30^{\prime} \mathrm{N}, 2^{\circ} 16^{\prime} \mathrm{E}\right)$ : 24.VI.2018 10 exx. (4m 6f) (PP).

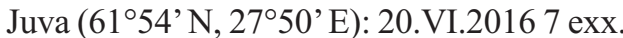
(AM).

Rantasalmi (62 $03^{\circ}$ N, $\left.28^{\circ} 18^{\prime} \mathrm{E}\right)$ : 9.VII.2017 6 exx. (AM).

Savonlinna $\left(61^{\circ} 53^{\prime}-56^{\prime} \mathrm{N}, 28^{\circ} 48^{\prime}-29^{\circ} 05^{\prime}\right.$ E): 14 observations in six places between 2016 and 2018. Most numerous 3.VI.2018 80 exx. (40 adults, 40 nymphs) (AM).

Joroinen $\left(62^{\circ} 13^{\prime} \mathrm{N}, 2^{\circ} 44^{\prime} \mathrm{E}\right)$ : 15. VII.2017 15 exx. (AM).

Leppävirta $\left(62^{\circ} 29^{\prime} \mathrm{N}, 27^{\circ} 47^{\prime} \mathrm{E}\right) 24$. VI.2018 5 exx. (AM).

Siilinjärvi (630' $\mathrm{N}, 27^{\circ} 40^{\prime}$ E) 24.VI.2018 17 exx. (AM).

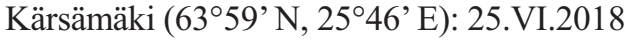
4 exx. (3 adults, 1 nymph) (PM). 


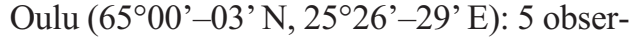
vations and 10 specimens in three places between 2014 and 2018 (PP, SH, PM, PR, AM, HN, MM). On Picea glauca in two places.

\subsection{A key to identify the Dichrooscytus species occurring in northern Europe}

1 Scutellum largely red or yellowish red.

- Scutellum green.

2 Rostrum reaching beyond hind coxae. Spicule of aedeagus as in Fig. 7c. Length 5.5-6.3 $\mathrm{mm}$.

D. rufipennis

- Rostrum shorter, not reaching beyond hind coxae. Spicule of aedeagus as in Fig. $7 b$. Length $4.5-5 \mathrm{~mm}$. D. intermedius

3 Rostrum reaching beyond hind coxae. Black pubescence on corium. Inner part of cuneus with a triangular patch of red extending as a narrow line along inner margin. Spicule of aedeagus as in Fig. 3. Length $4.8-5.3 \mathrm{~mm}$.

\section{D. fervens sp. n.}

- Rostrum shorter, reaching only middle coxae. Yellow pubescence on corium. Red in cuneus proximally as a narrow line and distally along inner margin. Spicule of aedeagus as in Fig. 7a. Length $3.7-4.4 \mathrm{~mm}$.

D. gustavi

\section{Discussion}

We described a novel heteropteran species, Dichrooscytus fervens sp. n. The species has many morphological diagnostic characters separating it from all the other known species. In addition, the genetic analysis supported its novel species status. The results also show that the Palaearctic species found in northern Europe (D. rufipennis, $D$. intermedius, $D$. gustavi and $D$. fervens sp. n.) are distinct from the analysed Nearctic species.

Dichrooscytus fervens sp. n. seems to be quite frequent and numerous at least in the southern part of the distribution area. However, the species was found in Kellarpelto, Savonlinna for the first time in 2017 although the hedge had been carefully studied annually between 2011 and 2017. It is probable that $D$. fervens $\mathbf{s p .} \mathbf{n}$. has spread there in recent years. The northern observations sug- gest that the species lives in Finland over a large area and the distribution pattern suggests that it lives also outside Finland at least in nearby areas.

Author contributions. A. M. had the original idea and found the new species. V. R. identified the new species and took all the pictures. E. V. carried out the laboratory and genetic analysis. A. M. wrote the first draft, and all authors wrote the final version of the manuscript

Acknowledgements. We thank the great bug lovers Petri Metsälä, Petri Parkko, Pekka Raukko and Tuomo Vainio for their co-operation. Sami Karjalainen, Brian Nelson and two anonymous reviewers gave valuable comments on the manuscript. We also thank Joseph Botting, Sami Haapala, Marko Mutanen, Harry Nyström, Laura Parkko and Sari Ralli for their help and support during this project.

\section{References}

Aljanabi, S. \& Martinez, I. 1997: Universal and rapid saltextraction of high quality genomic DNA for PCR-based techniques. - Nucleic Acids Research 25: 4692 4693. doi: https://doi.org/10.1093/nar/25.22.4692

Altschul, S. F., Gish, W., Miller, W., Myers, E. W. \& Lipman, D. J. 1990: Basic Local Alignment Search Tool. - Journal of Molecular Biology 215: 403-410. doi: https://doi.org/10.1016/S0022-2836(05)80360-2

Folmer, O., Black, M., Hoeh, W., Lutz, R. \& Vrijenhoek, R. 1994: DNA primers for amplification of mitochondrial cytochrome c oxidase subunit I from diverse metazoan invertebrates. - Molecular Marine Biology and Biotechnology 3: 294-299.

Günther, H. 1990: Contribution to the Heteroptera fauna of the Balkan peninsula. - Scopolia Supplement 1:3952.

Heiss, E. 1988: Heteropteren aus Kreta VI (Insecta, Heteroptera). - Bericht des Naturwissenschaftlich-Medizinischen Vereins in Innsbruck 75: 185-190. [In German.]

Hemiptera Expert Group 2018: Atlas of the Heteroptera of Finland. http://biolcoll.utu.fi/hemi/het/ludemaps.htm (Site visited on 8 November, 2018).

Henry, T. J. 2017. Biodiversity of Heteroptera. — In: Foottit, R. G. \& Adler, P. H. (eds.), Insect Biodiversity: Science and Society. Volume I. Second Edition: 279-336. John Wiley \& Sons. 904 pp. doi: https://doi.org/ 10.1002/9781118945568.ch10

Josifov, M. 1974: Beitrag zur Systematik der paläarktischen Dichrooscytus-Arten (Heteroptera - Miridae). - Reichenbachia 15: 149-173.

Josifov, M. 1981: Der verkannte Dichrooscytus valesianus Fieber, 1861 und der übersehene Dichrooscytus gusta$v i$ sp. n. aus Mitteleuropa (Heteroptera, Miridae). Reichenbachia 19: 43-45.

Kerzhner, I. M. 1997: Type specimens of some Palaearctic Miridae in the Zoological Museum, Helsinki (Heteroptera). - Zoosystematica Rossica 6: 115-121. 
Kerzhner, I. M. \& Josifov, M. 1999: Miridae: 1-577. — In: Aukema, B. \& Rieger, C. (eds.), Catalogue of the Heteroptera of the Palaearctic Region. Volume 3. Cimicomorpha II. Netherlands Entomological Society. Amsterdam. 577 pp.

Pilipenko, V. E., Salmela, J. \& Vesterinen, E. 2012: Description and DNA barcoding of Tipula (Pterelachisus) recondita $\mathrm{sp}$. $\mathrm{n}$. from the Palaearctic region (Diptera, Tipulidae). - ZooKeys 192: 51-65. doi: https:// doi.org/10.3897/zookeys.192.2364

Qi, B. \& Nonnaizab 1996: A new genus and two new species of Miridae from China (Hemiptera: Miridae). Acta Entomologica Sinica 39(3): 298-305.

Ratnasingham, S. \& Hebert, P. D. N. 2007: BOLD: The Barcode of Life Data System (www.barcodinglife.org). - Molecular Ecology Notes 7: 355-364. doi: https://doi.org/10.1111/j.1471-8286.2007.01678.x
Rintala, T. \& Rinne, V. 2011: Suomen luteet. Second Edition. - Tibiale, Helsinki, Finland. 352 pp.

Schuh, R. T. 2002-2013: On-line systematic catalog of plant bugs (Insecta: Heteroptera: Miridae). doi: http://research.amnh.org/pbi/catalog (Site visited on 29 November, 2018).

deWaard, J. R., Ivanova, N. V., Hajibabaei, M. \& Hebert, P. D. N. 2008: Assembling DNA Barcodes: Analytical Protocols: 275-293. — In: Martin, C. (ed.), Methods in molecular biology: Environmental genetics. Humana Press Inc., Totowa, USA. 364 pp.

Wagner, E. 1974: Zwei neue Miriden, Dichrooscytus inermis von Cyprus und Orthonotus creticus von Creta (Heteroptera, Miridae). — Beaufortia 21(284): 165171. 